\title{
Tacrine Sinusoidal Uptake and Biliary Excretion in Sandwich-Cultured Primary Rat Hepatocytes
}

Loqman A. Mohamed and Amal Kaddoumi

Department of Basic Pharmaceutical Science, School of Pharmacy, University of Louisiana at Monroe. 1800 Bienville Dr., Monroe, LA.

Received, May 22, 2014; Revised, August 15, 2014; Accepted, August 24, 2014; Published, August 24, 2014.

\begin{abstract}
PURPOSE. The knowledge of hepatic disposition kinetics of tacrine, a first cholinesterase inhibitor was approved by FDA for the treatment of Alzheimer's disease (AD), would help to understand its hepatotoxicity, its therapeutic effect, and improve the management of patients with AD. The current study aims to characterize tacrine hepatic transport kinetics and study the role of organic cation transporters (OCTs), Pglycoprotein (P-gp) and multidrug resistance-associated protein (MRP2) in tacrine sinusoidal uptake and biliary excretion. METHODS. Modulation of tacrine hepatic uptake and efflux, biliary excretion index (BEI\%), were performed in sandwich-cultured primary rat hepatocytes (SCHs) using transporters inhibitors. Conformation of the integrity of SCHs model was established by capturing images with light-contrast and fluorescence microscopy. RESULTS. Tacrine uptake in SCHs was carrier-mediated process and saturable with apparent $\mathrm{K}_{\mathrm{m}}$ of $31.5 \pm 9.6$ $\mu \mathrm{M}$ and $\mathrm{V}_{\max }$ of $908 \pm 72 \mathrm{pmol} / \mathrm{min} / \mathrm{mg}$ protein. Tetraethyl ammonium (TEA), cimetidine and verapamil significantly reduced tacrine uptake with more pronounced effect observed with verapamil which caused 3-fold reduction in tacrine uptake, indicating role for OCTs. Tacrine has a biliary excretion in SCHs with maximum $\mathrm{BEI} \%$ value of $22.9 \pm 1.9 \%$ at $10 \mathrm{~min}$ of incubation. Addition of MK571 and valspodar decreased the BEI\% of tacrine by 40 and $60 \%$ suggesting roles for canalicular MRP2 and P-gp, respectively. CONCLUSIONS. Our results show that in addition to metabolism, tacrine hepatic disposition is carrier-mediated process mediated by sinusoidal OCTs, and canalicular MRP2 and P-gp.
\end{abstract}

This article is open to POST-PUBLICATION REVIEW. Registered readers (see "For Readers") may comment by clicking on ABSTRACT on the issue's contents page.

\section{INTRODUCTION}

Tacrine (9-amino-1,2,3,4-tetrahydroacridine) was the first cholinesterase inhibitor approved by the US Food and Drug Administration (FDA) for the treatment of mild to moderate Alzheimer's disease (AD). Tacrine is an inhibitor for both cholinesterase enzymes, acetyl (AChE) and butyryl-cholinestrase (BChE); thereby, it is thought to increase brain level of acetylcholine and improve the cholinergic deficit observed in $\mathrm{AD}$ patients (1). Although tacrine therapy has shown improved psychomotor test scores in mild to moderately impaired AD patients, it was accompanied by serious hepatic adverse effects and significantly elevated hepatic transaminase concentrations in $25 \%$ of the patients $(2,3)$, and thus has a limited clinical application. Recently, novel tacrine analogues are extensively investigated in attempt to find less toxic compounds with multi-targeting mechanisms to AD pathology (4).
The liver toxicity of tacrine is indicated by the increase in serum alanine aminotransferase (ALT) activity $(5,6)$. Tacrine systemic clearance is mediated mainly by the liver, and several studies have determined its metabolism by CYP450 enzyme complex, mainly CYP1A2 (7, 8); however, no available studies have characterized hepatic transport kinetics and biliary excretion of tacrine. The knowledge of the hepatic disposition of tacrine would be useful in explaining its hepatotoxicity and provide further information to clinicians who can optimize the dose and improve the management of patients with AD. In humans, oral bioavailability of tacrine is $17-24 \%$, which is relatively low due to its first-pass metabolism (9).

Corresponding Author: Dr. Amal Kaddoumi, School of Pharmacy, University of Louisiana at Monroe, 1800 Bienville Dr., Monroe, LA; E-mail: kaddoumi@ulm.edu 
Tacrine clearance in human is mainly hepatic (10), while urine recovery of the sum of tacrine and its metabolites is less than $8 \% \quad(11)$. The pharmacokinetic profiles of tacrine are variable between individuals, and characterized by non-linear kinetics with low bioavailability at low doses (9).

Tacrine exerts its effect in the brain, and its transport across the blood-brain barrier (BBB) is carrier-mediated mainly through organic cation transporter 2 (OCT2) (12). Since tacrine is a cationic compound, it is conceivable that organic cation transporters (OCTs) contribute to its disposition throughout the body. OCTs are poly-specific organic cation transporters and belong to the SLC22 family. OCTs variable localization in the body, including intestine, liver, kidney and BBB, reflects their importance in mediating several biological and physiological functions. OCTs are involved in the uptake of many drugs from the small intestine and drug elimination across the liver and kidneys (13). On the canalicular side of hepatocytes, efflux transport proteins belong to the adenosine triphosphate (ATP)-dependent transport system (also known as the ATP-binding cassette (ABC) proteins), including P-glycoprotein (P-gp), multidrug resistance-associated protein (MRP2) (14), play an important role in biliary excretion of various drugs and/or metabolites.

To study the interplay of the basolateral and apical (canalicular) transporters in tacrine hepatic disposition, a polarized system is required which expresses the transport proteins at their domains. Sandwich-cultured hepatocytes are the only in vitro model that allows hepatocytes to form canalicular networks in cell culture. Sandwich-cultured hepatocytes are a powerful in vitro model that can be used to study drug hepatic transport, drug metabolism, drug-drug interaction, and hepatotoxicity (15). To evaluate the role of transporters in tacrine hepatobiliary disposition, we used primary rat hepatocytes cultured in sandwich configuration (SCHs). Transport proteins expression, localization and function in $\mathrm{SCH}$ have been extensively studied and the utility of this model to predict the biliary clearance and biliary excretion of several substances have been validated previously (16-18). In addition, biliary clearance values obtained for compounds using SCHs were found to correlate well with in vivo biliary clearance values measured with the same compounds in rats and humans (19-22).
Although several reports have indicated that tacrine is predominately metabolized into various hydroxylated metabolites via CYP450 system, none of these reports highlighted the transport-based clearance of tacrine by the liver. Hence, in this study we aimed to investigate the role of transport proteins in hepatic disposition of tacrine. Our findings demonstrated that, 1) in addition to metabolism, tacrine hepatic clearance is mediated by sinusoidal uptake and canalicular excretion by OCTs and the efflux transporters P-gp and MRP2, respectively, and 2) contribution of these transport proteins to tacrine hepatobiliary disposition could provide useful information to further understand reported hepatotoxicity and its non-linear pharmacokinetics profile.

\section{MATERIALS AND METHODS}

\section{Materials}

Tacrine hydrochloride and MK571 were obtained from Cayman Chemical Company (Ann Arbor, MI). Collagenase (type I, class I), rat tail collagen (type I), Dulbecco's modified Eagle's medium (DMEM), and insulin were purchased from Invitrogen (Carlsbad, CA). Fluvoxamine maleate, verapamil hydrochloride, 5 - ( and -6) - carboxy - 2' , 7 'dichlorofluorescein diacetate (CDFDA), dexamethasone, tetraethylammonium chloride (TEA), bovine serum albumin (BSA), soybean trypsin inhibitor, and fetal bovine serum (FBS) were purchased from Sigma-Aldrich (St. Louis, MO). ITS culture supplement $(10 \mu \mathrm{g} / \mathrm{ml}$ insulin, $10 \mu \mathrm{g} / \mathrm{ml}$ transferrin, $10 \mathrm{ng} / \mathrm{ml}$ selenous acid) was obtained from BD Biosciences (San Jose, CA). Valspodar was obtained from XenoTech (Lenexa, KS). Total protein measurement's reagents with the bicinchoninic acid (BCA) method were from Pierce (Rockford, IL). All other chemicals and reagents were of analytical grade and were readily available from commercial sources.

\section{Animals}

Male Sprague Dawley rats from Harlan Laboratories (Houston, TX) were used for the isolation of hepatocytes from entire livers. Rats age were around 2-3 months with average body weight between 260 to $340 \mathrm{~g}$. Animals were allowed to easy access for water and standard food and maintained at $22^{\circ} \mathrm{C}$, $35 \%$ relative humidity and $12 \mathrm{~h}$ dark/light cycle. All 
animal experiments were approved by the Institutional Animal Care and Use Committee of the University of Louisiana at Monroe and all surgical procedures were consistent with the IACUC policies and procedures.

\section{Isolation of primary rat hepatocytes and preparation of sandwich culture}

The isolation of hepatocytes from animals' livers were performed as previously described (23). After isolation of hepatocytes by several steps of centrifugation, cells were resuspended in serum-free medium and viability was determined using trypan blue method. Only hepatocytes with viability $\geq 80 \%$ were used in the preparation of sandwich culture. For SCHs preparation, plates were pre-coated with 50 $\mu \mathrm{g} / \mathrm{ml}$ collagen in $0.2 \mathrm{M}$ acetic acid solution, and left to dry overnight inside the hood. Before seeding the cells, 24 or 6 -well plates were neutralized by washing with sterile distilled water and hydrated by adding 0.5 or $1.5 \mathrm{ml} /$ well DMEM for 2 to $3 \mathrm{~h}$ at $37^{\circ} \mathrm{C}$. Hepatocytes were seeded at $0.7 \times 10^{6}$ cells $/ \mathrm{ml}$ and allowed to attach for 1 to $2 \mathrm{~h}$. The medium was then aspirated to remove unattached dead cells followed by addition of $0.5 \mathrm{ml} /$ well of fresh medium (DMEM supplemented with $5 \% \mathrm{FBS}, 100 \mathrm{U} / \mathrm{ml}$ penicillin, $100 \mathrm{~g} / \mathrm{ml}$ streptomycin, $4 \mathrm{mg} / 1 \mathrm{insulin}$, and $1 \mu \mathrm{M}$ dexamethasone) and incubated for $6 \mathrm{~h}$. Medium was then replaced with serum-free medium supplemented with $1 \%$ ITS, $100 \mathrm{U} / \mathrm{ml}$ penicillin, 100 $\mathrm{g} / \mathrm{ml}$ streptomycin, and $0.1 \mu \mathrm{M}$ dexamethasone. Twenty four hours later, hepatocytes were overlaid with $0.25 \mathrm{mg} / \mathrm{ml}$ matrigel in ice-cold medium and incubated at $37^{\circ} \mathrm{C}$ for $24 \mathrm{~h}$, after which medium was replaced with fresh medium everyday up to day 4 at which biliary excretion studies were performed.

\section{Light microscopy}

Images were taken at day 1 and day 4 of SCHs. The formation and integrity of canalicular networks were observed during culture and confirmed using phasecontrast microscopy, Nikon Eclipse TS100 inverted microscope from Nikon Instruments Inc. (Melville, NY).

\section{Fluorescence microscopy}

At day 4 of SCHs, 5-(and-6)-carboxy-2',7'dichlorofluorescein diacetate (CDFDA) was used as a canalicular marker. Plates were rinsed with standard HBSS and incubated in the same buffer for 10 minutes. The buffer was aspirated and replaced with $2 \mu \mathrm{M}$ CDFDA dissolved in HBSS containing 5
$\mathrm{mM} \mathrm{CaCl} 2$ and incubated at $37^{\circ} \mathrm{C}$ for 10 minutes. Treatment was removed and cells were washed 4 times with ice-cold standard HBSS. Images were taken for the canalicular fluorescent metabolite (CDF) using fluorescence microscope (Nikon Eclipse) at 20x magnification.

\section{Time and concentration-dependent uptake of tacrine in SCHs}

Time and concentration-dependent studies of tacrine were determined in day 1 of SCHs (no canalicular spaces were formed thus only uptake process can be investigated) (23). To determine the optimum time for tacrine uptake, SCHs were first gently washed with standard HBSS twice and then incubated with 1 $\mu \mathrm{M}$ tacrine for designated time points $(2,5,10$ and $30 \mathrm{~min})$. Treatment was removed and cells were washed 3 times with ice-cold HBSS. Cells were lysed by adding $200 \mu 11 \%$ Triton X-100 containing $1 \%$ protease inhibitors cocktail, and intracellular accumulation of tacrine at each time point was determined by HPLC analysis as described below. To examine the saturable and non-saturable (passive) part of tacrine uptake in SCHs, cells were treated with increasing concentrations of tacrine at 4 and $37^{\circ} \mathrm{C}$. SCHs were incubated with $0.5 \mathrm{ml}$ of tacrine $(0.1-500 \mu \mathrm{M})$ dissolved in standard HBSS in 24-well plates, at 4 and $37^{\circ} \mathrm{C}$, for passive and active uptake, respectively. Michaelis-Menten parameters of the saturable uptake of tacrine were determined by subtracting uptake at $4^{\circ} \mathrm{C}$ from uptake at $37^{\circ} \mathrm{C}$ to obtain the saturable active process that was plotted against concentration.

Inhibition of tacrine sinusoidal uptake in SCHs

To investigate the role of OCTs that may involve tacrine hepatic uptake, inhibition studies were performed on day 1 of SCHs. SCHs were treated with several OCTs modulators including TEA 300 $\mu \mathrm{M}$, cimetidine $300 \mu \mathrm{M}$, verapamil (10, 50 and 100 $\mu \mathrm{M})$ and fluvoxamine $(2,10$ and $50 \mu \mathrm{M})$. Cells were pre-incubated with inhibitors for $30 \mathrm{~min}$ to allow access of inhibitors to their targeted transporters. Subsequently, $1 \mu \mathrm{M}$ tacrine were added along with the inhibitors and incubated for $5 \mathrm{~min}$. Cells were washed 3 times with ice-cold HBSS and lysed. For CYP1A2 inhibition, cells were pre-incubated with 2, 10 and $50 \mu \mathrm{M}$ of fluvoxamine for $30 \mathrm{~min}$ and subsequently, uptake was initiated by replacing medium with $1 \mu \mathrm{M}$ tacrine and incubated for $2 \mathrm{~h}$. 


\section{Uptake of tacrine at different pHs}

For $\mathrm{pH}$-dependent uptake experiments, $1 \mu \mathrm{M}$ tacrine was incubated for $5 \mathrm{~min}$ at different $\mathrm{pHs}$ including 6.4, 7.4 and 8.4. At the end of the experiments, medium was aspirated and cells were washed 3 times with ice cold standard HBSS while keeping plates on ice. Cells were lysed and quantitative determination of intracellular tacrine was performed by HPLC as described below.

\section{Determination of tacrine biliary excretion index (BEI\%) and biliary clearance $\left(\mathrm{Cl}_{\text {bile }}\right)$}

All experiments were conducted on day 4 of sandwich culture (17). Six well plates were washed twice with warm standard or $\mathrm{Ca}^{++}$-free HBSS (to maintain or break the canalicular networks) and incubated in their respective buffers for $5 \mathrm{~min}$. Subsequently, $2 \mathrm{ml}$ of tacrine in standard or $\mathrm{Ca}^{++}-$ free HBSS were added to cell culture plates and incubated for $5-30 \mathrm{~min}$, at $37^{\circ} \mathrm{C}$, to determine the time for maximum biliary excretion of tacrine. Plates were washed 3 times with ice-cold HBSS and lysed. Data were normalized to protein content in each well using BCA protein assay kit and BSA was used as standard. In addition, the results were normalized to tacrine non-specific binding to matrigel by subtracting tacrine bound to matrigel coated wells without cells, which was less that $4 \%$.The obtained data from the accumulation experiments of tacrine, in the presence or absence of calcium, were used to calculate BEI\% using equation 1, and biliary clearance $\left(\mathrm{Cl}_{\text {bile }}\right)$ using equation 2 , described below under data analysis.

\section{Effect of P-gp and MRP2 modulation on canalicular efflux of tacrine}

SCHs, day 4 of culture, were washed twice with HBSS with or without calcium and incubated for 5 min. Subsequently, cells were pre-treated with $5 \mu \mathrm{M}$ valspodar as P-gp inhibitor, or $10 \mu \mathrm{M}$ MK571 as MRP2 inhibitor, followed by incubation of tacrine with the inhibitors for 10 min (maximum tacrine BEI\%). Cells were lysed using 1\% Triton X-100 containing $1 \%$ protease inhibitors cocktail, by shaking on rocking platform for $1 \mathrm{~h}$ at room temperature. Intracellular tacrine concentrations were measured using HPLC.

\section{HPLC analysis of tacrine}

Tacrine quantification was determined by modification of previously published method (24). Tacrine concentrations from cells lysate and media were determined using an isocratic Prominence Shimadzu HPLC system (Columbia, MD) consisted of SIL 20-AHT autosampler, LC-20AB pump connected to a Dgu-20A3 degasser, and an RF10A $\mathrm{XL}$ fluorescent detector. Data acquisition was achieved by LC Solution software version 1.22 SP1. Tacrine was first extracted from the cell lysate by vortex mixing with $1: 1$ acetonitrile followed by centrifugation at $10000 \mathrm{~g}$ for $10 \mathrm{~min}$. Samples of 100 $\mu \mathrm{l}$ from clear supernatant were loaded into inserts for analysis. Samples were separated using an Eclipse XDB-C18 column $(150 \times 4.6 \mathrm{~mm}$ i.d., $5 \mu \mathrm{m}$ particle size; Agilent, CA, USA) with a mobile phase consisted of acetonitrile and $0.02 \mathrm{M}$ phosphate buffer pH $2.5(20: 80, \mathrm{v} / \mathrm{v})$ at a flow rate of $1.0 \mathrm{ml} / \mathrm{min}$. Samples injection volumes were $20 \mu 1$. Fluorescence detection was performed at an excitation wavelength of $240 \mathrm{~nm}$ and emission wavelength of $360 \mathrm{~nm}$. The total run time was $5 \mathrm{~min}$ with tacrine retention time at $2.9 \mathrm{~min}$. The analytical method was found to be linear in the studied range $(0.01-2 \mu \mathrm{M})$ with lower limit of quantification of $10 \mathrm{nM}$, and precise with coefficient of variation $(\% \mathrm{CV})$ less than $10 \%$.

\section{DATA ANALYSIS}

B-CLEAR technology (Qualyst, Inc., Research Triangle Park, NC) was used to calculate the biliary excretion index (BEI), and was determined by the cumulative uptake method as previously described (16). Uptake of a substrate prepared in calcium containing buffer represents its accumulation into cells and canalicular lumen, while uptake in calciumfree buffer represents its accumulation into cells only. The difference in readings between both treatments was used to calculate the $\mathrm{BEI} \%$ and $\mathrm{Cl}_{\text {bile }}$ as shown in equations 1 and 2 , respectively. In equation $2, \mathrm{AUC}_{\text {medium }}$ was determined as the product of the incubation time and substrate initial concentration in the incubation medium.

$$
\begin{aligned}
& \mathrm{BEI} \%=\frac{\text { Accumulation into cells }+ \text { canaliculi }\left(+\mathrm{Ca}^{++}\right)-\text {Accumulation into cells }\left(-\mathrm{Ca}^{++}\right)}{\text {Accumulation into cells }+ \text { Canaliculi }\left(+\mathrm{Ca}^{++}\right)} \times 100 \\
& \mathrm{Cl}_{\text {bile }}=\frac{\text { Accumulation into cells }+ \text { canaliculi }\left(+\mathrm{Ca}^{++}\right)-\text {Accumulation into cells }\left(-\mathrm{Ca}^{++}\right)}{\mathrm{AUC}_{\text {medium }}}
\end{aligned}
$$


Biliary clearance values have a unit of $\mathrm{ml} / \mathrm{min} / \mathrm{kg}$ of body weight, based on $200 \mathrm{mg}$ of protein/g of liver and $40 \mathrm{~g}$ of liver $/ \mathrm{kg}$ of rat body weight (25). The Michaelis-Menten constant $\left(K_{\mathrm{m}}\right)$ and the maximum transport rate $\left(V_{\max }\right)$ were estimated using Prism 5 for windows, version 5.03 from GraphPad Software, Inc. (La Jolla, CA).

\section{STATISTICAL ANALYSIS}

Unless otherwise indicated, all data were expressed as mean \pm SEM. The experimental results were statistically analyzed for significant difference using unpaired two-tailed Student's t-test for comparison between two groups, and one-way analysis of variance (ANOVA) followed by Dunnett's post-hoc test for analysis of more than two groups. A P-value of less than 0.05 was considered statistically significant.

\section{RESULTS}

\section{Phase-contrast image of SCHs}

Light microscopy images were captured on day 1 and day 4 of SCHs. At day 1 of SCHs (Figure 1a), cells start to close to each other; however, canalicular spaces were not formed yet and the model is suitable to perform uptake studies. On the other hand, on day 4 of SCHs (Figure 1b), canalicular spaces were formed extensively as indicated by the yellow arrows (canaliculi appear as bright white spaces), and their transport proteins are localized to their apical domains, which is suitable to perform biliary excretion studies.

\section{SCHs model validation}

In addition to the light microscopy imaging, we validated the functionality of our model using the canalicular marker, CDFDA. CDFDA is passively uptaken into hepatocytes and rapidly metabolized into 5-(and-6)-carboxy-2',7'-dichlorofluorescein (CDF), a fluorescent metabolite, which is actively effluxed into the canalicular spaces via MRP2 (16). As shown in Figure $1 \mathrm{c}$, CDF was intensely accumulated into the canalicular network, indicated by the arrows as green fluorescent color, which confirms the formation of canalicular spaces that are sealed by the tight junctions under the above mentioned condition.

\section{Kinetics of tacrine uptake in SCHs}

As shown in Figure 2 a, the uptake of $1 \mu \mathrm{M}$ tacrine was rapid and time dependent reaching a plateau at $10 \mathrm{~min}$. Thus, for further characterization of tacrine uptake with modulators all consequent uptake studies were performed at $5 \mathrm{~min}$. In addition, the uptake of tacrine in SCHs under the specified conditions was saturable process (Figure $2 \mathrm{~b}$ ), with apparent $\mathrm{K}_{\mathrm{m}}$ value of $31.5 \pm 9.6 \mu \mathrm{M}$ and $\mathrm{V}_{\max }$ of $908 \pm 72 \mathrm{pmol} / \mathrm{min} / \mathrm{mg}$ protein (Table I).

\section{Effect of OCTs inhibition on tacrine sinusoidal uptake}

To examine the contribution of OCTs to the uptake of tacrine, cells were treated with different cations (Figure 3 a). Cimetidine at $300 \mu \mathrm{M}$, verapamil and fluvoxamine at $50 \mu \mathrm{M}$ concentration inhibited tacrine uptake by $>50 \%$ of its initial uptake, while the inhibitory effect of $300 \mu \mathrm{M}$ TEA on tacrine uptake was less pronounced, but significant $(\mathrm{P}<0.05)$, and decreased tacrine uptake by $\sim 18 \%$ compared to untreated control. In addition, verapamil inhibited tacrine uptake in a concentration-dependent manner (Figure $3 \mathrm{~b}$ ) with maximal inhibition at $100 \mu \mathrm{M}(\mathrm{P}<0.001)$. These results indicate a role of the organic cation transport proteins, OCTs, localized at the sinusoidal side of hepatocytes involved in the saturable uptake of tacrine.

Pre-treatment of SCHs with 2, 10 and $50 \mu \mathrm{M}$ fluvoxamine followed by $5 \mathrm{~min}$ co-incubation with 1 $\mu \mathrm{M}$ tacrine caused a concentration-dependent reduction in tacrine uptake with approximately 2fold reduction at $50 \mu \mathrm{M}$ fluvoxamine (Figure $4 \mathrm{a}$ ), suggesting an inhibitory effect on tacrine sinusoidal uptake. In addition, SCHs pre-treatment with 2, 10 and $50 \mu \mathrm{M}$ fluvoxamine, a CYP1A2 inhibitor, followed by $2 \mathrm{~h}$ incubation with $1 \mu \mathrm{M}$ tacrine resulted in significant increase in tacrine intracellular accumulation only at $50 \mu \mathrm{M}$ fluvoxamine $(\mathrm{P}<0.001$; Figure $4 \mathrm{~b}$ ) due to its inhibitory effect on tacrine metabolism. These results suggest fluvoxamine inhibitory effect on tacrine sinusoidal uptake in $\mathrm{SCHs}$ is greater than its effect on CYP1A2 inhibition. 


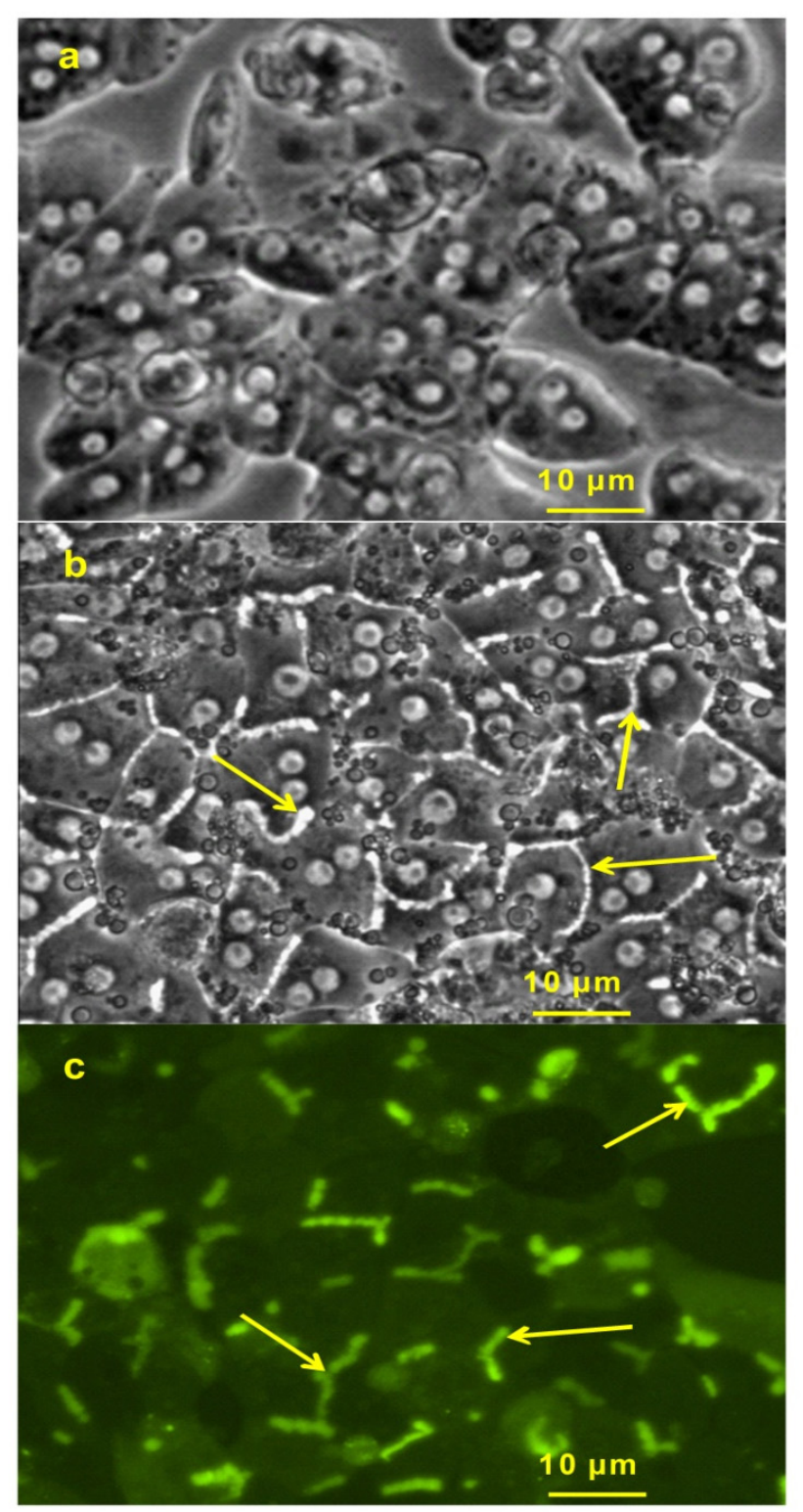

Figure 1. Phase-contrast and fluorescence images of SCHs cultured for 1 (a) or 4 (b \& c) days. No canalicular spaces were formed on day 1 of SCHs (a), but they were formed extensively by day 4 as indicated by the yellow arrows as bright white lines (b). Canalicular spaces are shown as intense green fluorescent color (c) due to accumulation of the canalicular marker CDF. Scale bars $=$ $10 \mu \mathrm{m}$.

\section{pH-dependent uptake of tacrine}

Incubation of tacrine at different $\mathrm{pHs}$ demonstrated a pH-dependent increase in the uptake of tacrine with average uptake values of $68 \pm 4,405 \pm 16$ and $816 \pm 62$ $\mathrm{pmol} / \mathrm{min} / \mathrm{mg}$ protein, at $\mathrm{pH} 6.4,7.4$ and 8.4 , respectively. a

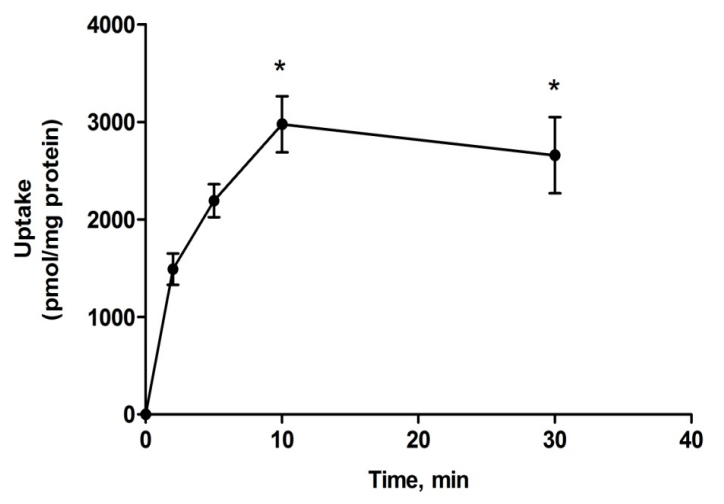

b

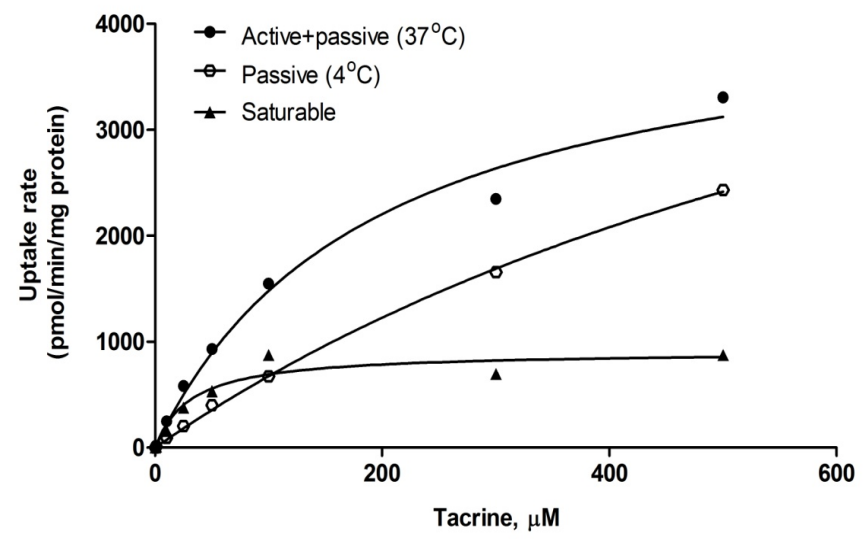

Figure 2. Time and concentration dependant uptake of tacrine. (a) Cellular uptake of $1 \mu \mathrm{M}$ tacrine in SCHs at day 1. Points represent cumulative uptake for $\mathrm{n}=4$ at different treatment times, $* \mathrm{P}<0.05$ compared to 2 and 5 min, based on unpaired Student's $t$ test. (b) Uptake rate of tacrine at different concentrations in SCHs on day 1 at 4 and $37^{\circ} \mathrm{C}$ showing non-linear pattern.

\section{Determination of tacrine biliary excretion and clearance}

$\mathrm{SCHs}$, day 4, were used to characterize tacrine biliary excretion. As shown in Figure 5, tacrine biliary excretion was evident and was timedependent reaching maximum biliary excretion at 10 min with BEI value of $22.9 \%$. The biliary clearance $\left(\mathrm{Cl}_{\text {bile }}\right)$ of tacrine was $275 \pm 12 \mathrm{ml} / \mathrm{min} / \mathrm{kg}$, as calculated using equation 2 shown under data analysis.

\section{Effect of P-gp and MRP2 inhibition on canalicular efflux of tacrine}

Tacrine biliary excretion was further characterized to elucidate its canalicular efflux mechanism(s) in 
SCHs. The canalicular P-gp role in tacrine biliary excretion was tested by incubating cells with $5 \mu \mathrm{M}$ valspodar which significantly reduced the BEI\% of $1 \mu \mathrm{M}$ tacrine by approximately $60 \%$ from $22.9 \pm 1.9$ to $9.2 \pm 3.1 \%$. In addition, tacrine canalicular efflux was inhibited by $10 \mu \mathrm{M}$ MK571, and was reduced by approximately $40 \%$ from $22.9 \pm 1.9$ to $13.8 \pm 4.1 \%$. These results suggest a role for P-gp and MRP2 in tacrine biliary excretion (Figure 6).

a

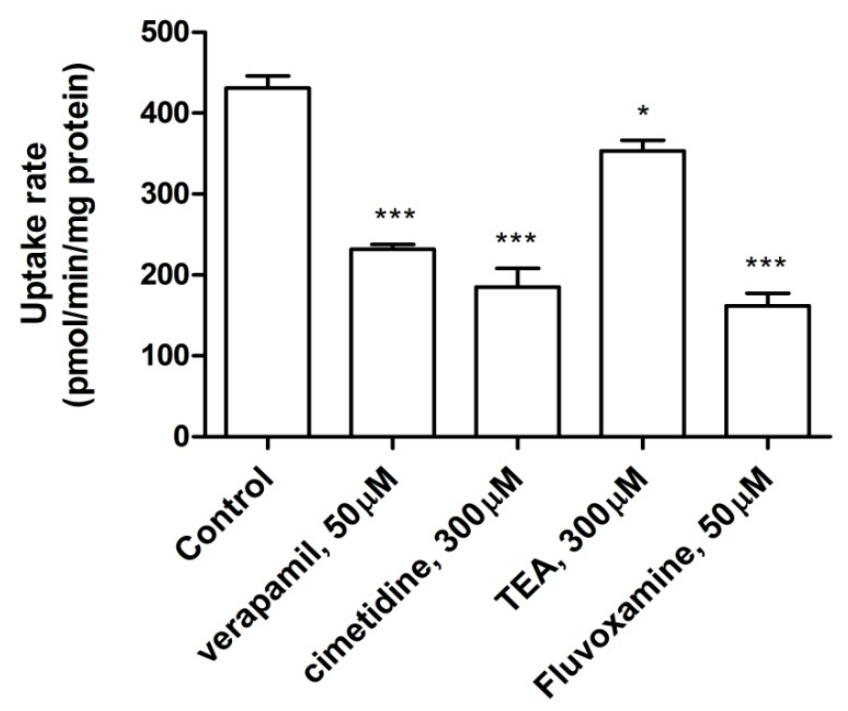

b

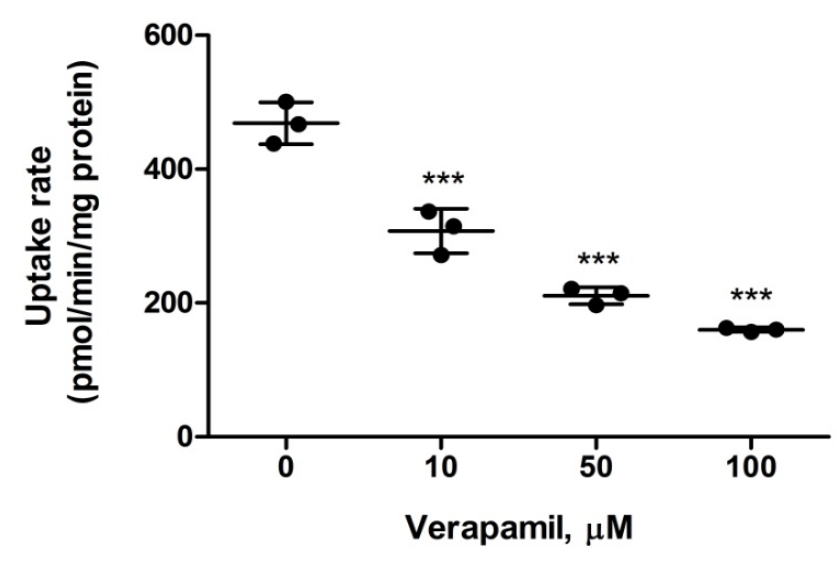

Figure 3. Effect of co-incubation of different OCTs inhibitors on tacrine uptake. (a) Effect of cimetidine, verapamil, TEA, and fluovoxamine on the uptake rate of tacrine in SCHs at day 1. (b) Concentration-dependent inhibition of verapamil on the uptake rate of tacrine in $\mathrm{SCH}$ at day 1 . Points represent mean $\pm \mathrm{SEM}$ for triplicates from two independent experiments. ${ }^{*} \mathrm{P}<0.05$ and $* * *$ $\mathrm{P}<0.01$ compared to untreated control.

\section{DISCUSSION}

Tacrine was used in the treatment of patients with $\mathrm{AD}$, and its mechanism of transport from blood to brain across the BBB was previously investigated (12). The systemic elimination of tacrine is mainly mediated by the liver (10). Several reports have indicated the elimination pathway of tacrine by the liver is mainly metabolism (7); however, the role of hepatic transport proteins in the hepatobiliary excretion of tacrine is poorly understood.

In this study we used SCHs model to investigate the contribution of hepatic transport proteins to the hepatic disposition and biliary clearance of tacrine. As several studies, which focused on transporters contribution to the hepatobiliary disposition of drugs, demonstrated a remarkable agreement between human and rats data $(26,27)$, in the current study hepatocytes isolated from rats were utilized.

The formation of intact canalicular networks in $\mathrm{SCHs}$ were confirmed by capturing light-contrast microscopy images at day 4 of SCHs (Figure 1b). In addition, CDFDA was used as a canalicular marker that showed the integrity and functionality of the model to perform biliary excretion experiments (Figure 1c). CDFDA has been used extensively as a canalicular marker in the assessment of MRP2 function and canalicular network formation in SCHs (18). Using SCHs, we were able to demonstrate the role of active transport processes in the sinusoidal uptake as well as the canalicular efflux of tacrine. Tacrine has a pKa value of 9.4 (28); therefore, it is positively charged at physiologic $\mathrm{pH}$. Findings from the uptake studies demonstrated that tacrine cellular uptake is a saturable process and is mediated by the organic cationic transporters, OCTs, which are expressed on the sinusoidal side of hepatocytes (13). OCTs transport substances that are relatively hydrophilic, low molecular mass and are organic cations. Inhibition studies with TEA, a prototypical substrate and inhibitor of OCT subclasses members (13), verapamil and cimetidine supported contribution of OCTs to the uptake of tacrine in $\mathrm{SCHs}$. These results are in agreement with previous reports indicated that OCTs play a major role in mediating the transport of tacrine across the BBB using LLC-PK1 cells (12). However, verapamil has been shown to inhibit not only OCTs but also OATPs (29). 
Table 1. Kinetic Transport Parameters of Tacrine.

\begin{tabular}{lccc}
\hline Condition & Kinetic Parameter & Unit & \\
\hline SCHs, day 1 H $^{\#}$ & & & $908 \pm 72$ \\
Uptake & $\mathrm{V}_{\max }$ & pmol/min/mg protein & $31.5 \pm 9.6$ \\
SCHs, day 4* & $\mathrm{K}_{\mathrm{m}}$ & $\mu \mathrm{M}$ & $22.9 \pm 1.9$ \\
& & & $275 \pm 12$ \\
\hline
\end{tabular}

\# At day 1 of SCHs, cells form a monolayer while canalicular spaces are negligible and hence it is suitable to perform uptake studies. * After 4 days of culture, SCHs form intact canalicular spaces and the model is suitable to perform canalicular efflux studies.

a

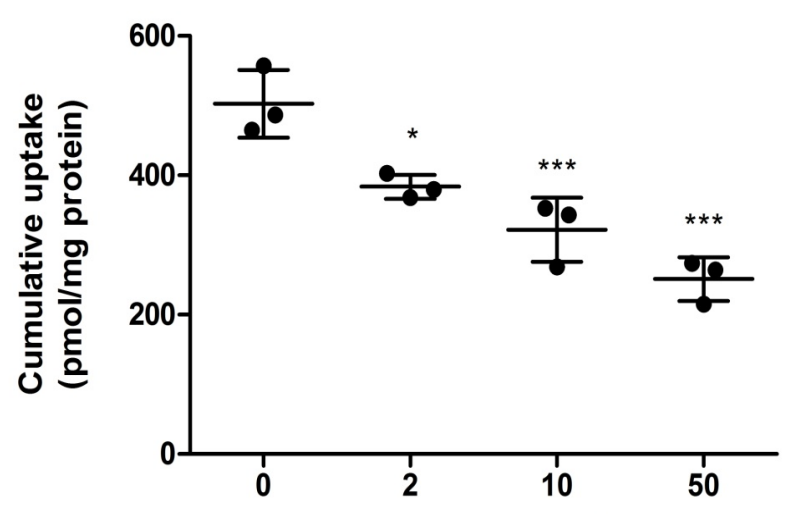

Fluvoxamine, $\mu \mathrm{M}$

b

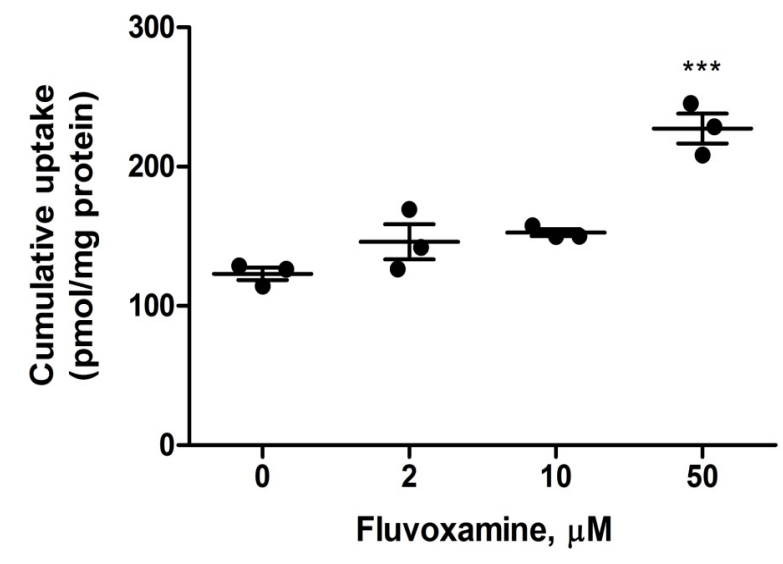

Figure 4. Effect of fluvoxamine on tacrine uptake in SCHs at day 1. (a) Concentration-dependent inhibition of fluvoxamine on the cumulative uptake of tacrine. Hepatocytes were pre-incubated with fluvoxamine for 30 min followed by uptake of $1 \mu \mathrm{M}$ tacrine for $5 \mathrm{~min}$. * $\mathrm{P}<0.05$, *** $\mathrm{P}<0.01$ compared to untreated control. (b) Pre-incubation of SCHs with increasing concentration of fluvoxamine for $30 \mathrm{~min}$ followed by uptake of $1 \mu \mathrm{M}$ tacrine for 2 h. $* * * \mathrm{P}<0.01$ compared to untreated control.

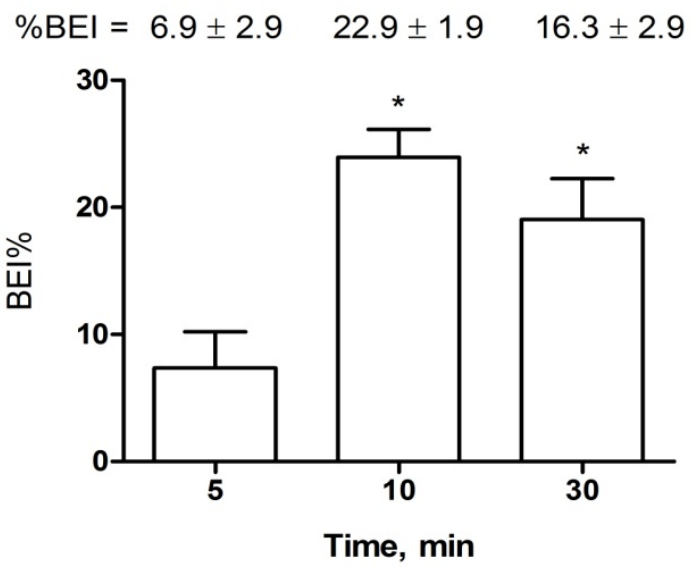

Figure 5. Representative time course of tacrine biliary excretion index $(\mathrm{BEI} \%)$ in $\mathrm{SCH}$ at day 4 . BEI\% value of $1 \mu \mathrm{M}$ tacrine was calculated at each time point. Bars represent the mean $\pm \operatorname{SEM}(\mathrm{n}=3),{ }^{*} \mathrm{P}<0.05$ compared to $5 \mathrm{~min}$, based on unpaired Student's $t$ test.

$$
\% \mathrm{BEI}=22.9 \pm 1.9 \quad 9.2 \pm 3.1 \quad 13.8 \pm 4.1
$$

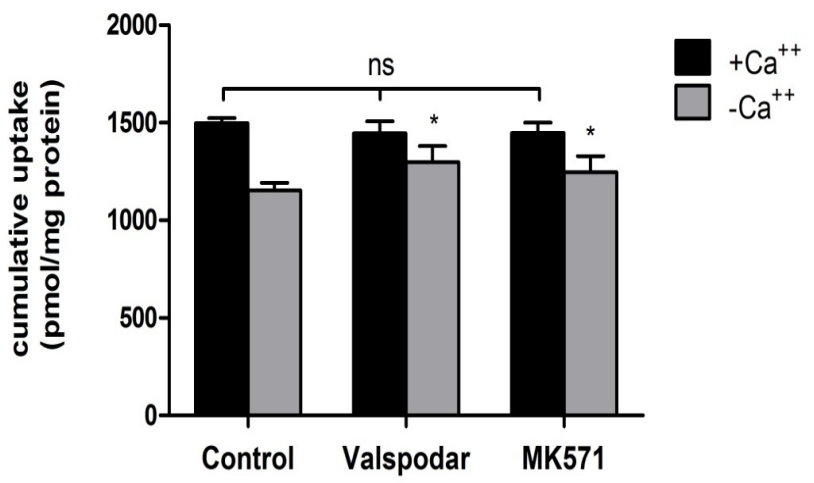

Figure 6. Effect of P-gp (valspodar) and MRP2 (MK571) inhibition on the cumulative uptake and BEI\% of $1 \mu \mathrm{M}$ tacrine. Cumulative uptake of tacrine was determined after $10 \mathrm{~min}$ incubation in SCHs at day 4. Bars represent the mean $\pm \operatorname{SEM}(\mathrm{n}=4)$, ns $=$ not significant, $* * \mathrm{P}<0.01$ compared to corresponding control. 
Nonetheless, the contribution of OATPs in mediating tacrine uptake was rolled out by inhibition studies with rifampicin, a known OATPs inhibitor (30), which did not alter tacrine cellular accumulation (data not shown). Hence, the reduction in tacrine uptake caused by inhibition with verapamil was attributed mainly to OCTs inhibition. Verapamil, TEA and cimetidine have shown to inhibit OCT members including OCT1-3 and OCTN2 expressed in different cell lines $(13,31,32)$. However, as OCT2 has not been detected in rats' hepatocytes [10], our results demonstrated tacrine as a substrate for OCT1, OCT3 and/or OCTN2. In addition, our data showed that tacrine uptake was $\mathrm{pH}$ dependent with approximately 3 -fold decrease in acidic $\mathrm{pH}(6.4)$ and 2-fold increase in alkaline $\mathrm{pH}$ (8.6) compared to uptake at neutral $\mathrm{pH}$ (7.4). Among the OCT transporters expressed in the liver, OCTN1 and OCTN2 were reported to be $\mathrm{pH}$-dependent, and they transport cations by a proton antiport mechanism (33-36). Like OCTN2, OCTN1 has been reported to mediate the transport of several compounds including verapamil and TEA (33), however its cellular localization has not been confirmed yet. Collectively, the saturable uptake of tacrine by hepatocytes could be attributed to OCTs family members including OCT1, OCT3 and OCTN1/2.

Tacrine hepatic metabolism is mainly mediated by CYP1A2. Tacrine metabolism was only inhibited by $\mathrm{SCHs}$ pre-treatment with fluvoxamine which caused a 2-fold increase in tacrine intracellular accumulation (Figure $4 \mathrm{~b}$ ). However, this increase was not observed when tacrine was co-incubated with fluvoxamine, rather its uptake was reduced by approximately 2-fold, (Figure 4 a). These results suggest that when fluvoxamine was co-incubated with tacrine, fluvoxamine inhibited tacrine uptake and decreased its intracellular accumulation, while when cells were pre-treated first with fluvoxamine and then treated with tacrine alone, this allowed for CYP1A2 inhibition and decreased tacrine intracellular concentration. Hence, fluvoxamine could interfere not only with tacrine hepatic metabolism, but also with its sinusoidal uptake probably via OCTs.

In addition to hepatic metabolism, our results suggested elimination of tacrine into the bile. This was evident by biliary excretion experiments in $\mathrm{SCH}$, where tacrine BEI\% was estimated to be about 23\% (Figure 5). To investigate transporters involved in the biliary excretion of tacrine, P-gp role was studied. P-gp is localized at the canalicular domain of rat SCHs (17), and it is primarily responsible for the biliary excretion of organic cations and neutral molecules (37). In our experiments, the canalicular efflux of tacrine decreased significantly when co-incubated with 5 $\mu \mathrm{M}$ valspodar by approximately $60 \%(\mathrm{P}<0.01$; Figure 6) supporting a role for the canalicular P-gp in mediating tacrine biliary excretion. The inhibition of tacrine efflux by valspodar can also be noticed from the increased accumulation of tacrine in the absence of calcium, where the tight junctions are broken and their content is released into the medium. Hence, inhibition of P-gp efflux function by valspodar resulted in more intracellular accumulation of tacrine compared to untreated control. The inhibitory effect of valspodar on P-gp function in $\mathrm{SCHs}$ is consistent with our previous report (23). A previous work, however, by Doan and colleagues demonstrated that tacrine is not a P-gp substrate based on permeability screening studies for 93 compounds performed on MDR1-transfected MDCK type II cells (38). They found that the permeability of $10 \mu \mathrm{M}$ tacrine following $1 \mathrm{~h}$ treatment was not altered by $1 \mu \mathrm{M}$ elacridar, a P-gp inhibitor. This discrepancy in the results could be attributed to differences in the experimental design, type of cells, and concentration of tacrine that were used.

MRP2 is another efflux transporter localized at the canalicular side of SCHs and was investigated in our study as a potential transporter to play a role in tacrine biliary excretion. P-gp and MRP2 are important in the elimination of many endogenous and exogenous xenobiotics and they have overlapping substrate specificity (39). MK571, an MRP2 inhibitor, caused $40 \%$ reduction in the BEI\% of tacrine, suggesting a role for MRP2 in mediating tacrine canalicular excretion. The biliary excretion of tacrine mediated by P-gp and MRP2 could be clinically important. Several endogenous and exogenous molecules are substrates for P-gp and MRP2, and may competitively inhibit tacrine biliary excretion. Although bile-mediated hepatic clearance of tacrine is moderate, failure in this mechanism by transport competition or due to disorders such as hepatic or gallbladder diseases could increase hepatic levels of tacrine hence increasing the risk of hepatotoxicity. Likewise, many endogenous amines (e.g., epinephrine, dopamine, and choline) and exogenous drugs (e.g., quinidine, vancomycin, procainamide, digoxin, trimethoprim and 
metformin) are cationics (positively charged at physiologic $\mathrm{pH}$ ) and thus have the potential to interact, and may compete, with tacrine for hepatic extraction. Moreover, the involvement of uptake and efflux transporters in tacrine hepatobiliary disposition could explain, at least in part, the nonlinear kinetic behavior observed with tacrine at different doses (9). In addition to metabolism, tacrine hepatic uptake and excretion are active and saturable processes, thus at low doses, tacrine hepatic extraction is more efficient resulting in low bioavailability; however, at higher doses, tacrine could saturate its own hepatic uptake, metabolism and/or biliary excretion resulting in enhanced bioavailability. As P-gp and OCTs transport proteins are also expressed in the endothelial cells of the $\mathrm{BBB}$, they are expected to play an important role in controlling tacrine transport into and out of the brain. A previous study has shown the involvement of OCTs in the transport of tacrine across the BBB of rats with major contribution of OCT2 (12); however, the role of P-gp in this process remains to be investigated.

The obtained results in this study demonstrated a role for transport proteins in mediating tacrine hepatobiliary disposition that could be valuable for further consideration to understand its hepatotoxicity and its non-linear pharmacokinetic profile. Nonetheless, animal studies are required for further confirmation of the role of these transport proteins in tacrine hepatic clearance in vivo and for any possible drug-drug interaction at the transport level. In conclusion, tacrine uptake by hepatocytes is a saturable process with multiple mechanisms mediated, at least in part, by OCTs family members, and its uptake is $\mathrm{pH}$ and temperature dependent. In addition to clearance of tacrine by metabolism, biliary excretion of the parent compound is evident and mediated by P-gp and MRP2.

\section{ACKNOWLEDGEMENT}

This research work was funded by an Institutional Development Award (IDeA) from the National Institute of General Medical Sciences of the National Institutes of Health under grant number P20GM103424.

\section{ABBREVIATIONS}

$\mathrm{BEI} \%$, biliary excretion index; $\mathrm{BBB}$, blood-brain barrier; $\mathrm{BSA}$, bovine serum albumin; $\mathrm{Cl}_{\text {bile, }}$, biliary clearance; CDFDA, 5-(and-6)-carboxy-2',7'dichlorofluorescein diacetate; CDF, 5-(and-6)carboxy-2',7'-dichlorofluorescein; DMEM, Dulbecco's modified Eagle's medium; EGTA, ethylene glycol tetraacetic acid; FBS, fetal bovine serum; HBSS, Hanks Balanced Salt Solution; MK571, 5-(3-(2-(7-chloroquinolin-2-yl) ethenyl) phenyl)-8-dimethylcar-bamyl-4,6-dithiaoctanoic acid; MRP2, multidrug resistance-associated protein 2; OCT, organic cation transporter; P-gp, Pglycoprotein; SCHs, sandwich cultured primary rat hepatocytes; TEA, tetraethyl ammonium.

\section{REFERENCES}

1. Wilkinson DG, Francis PT, Schwam E, PayneParrish J. Cholinesterase inhibitors used in the treatment of Alzheimer's disease: the relationship between pharmacological effects and clinical efficacy. Drugs Aging, 2004; 21(7):453-78.

2. Crismon ML. Tacrine: first drug approved for Alzheimer's disease. Ann Pharmacother, 1994; 28(6):744-51.

3. Farlow M, Gracon SI, Hershey LA, Lewis KW, Sadowsky CH, Dolan-Ureno J. A controlled trial of tacrine in Alzheimer's disease. The Tacrine Study Group. JAMA, 1992; 268(18):2523-9.

4. Korabecny J, Spilovska K, Benek O, Musilek K, Soukup O, Kuca K. [Tacrine and its derivatives in the therapy of Alzheimers disease]. Ceska Slov Farm, 2012; 61(5):210-21.

5. Arrieta JL, Artalejo FR. Methodology, results and quality of clinical trials of tacrine in the treatment of Alzheimer's disease: a systematic review of the literature. Age Ageing, 1998; 27(2):161-79.

6. Watkins PB, Zimmerman HJ, Knapp MJ, Gracon SI, Lewis KW. Hepatotoxic effects of tacrine administration in patients with Alzheimer's disease. JAMA, 1994; 271(13):992-8.

7. Madden S, Woolf TF, Pool WF, Park BK. An investigation into the formation of stable, proteinreactive and cytotoxic metabolites from tacrine in vitro. Studies with human and rat liver microsomes. Biochem Pharmacol, 1993; 46(1):13-20.

8. Woolf TF, Pool WF, Bjorge SM, Chang T, Goel OP, Purchase CF, 2nd, et al. Bioactivation and irreversible binding of the cognition activator tacrine using human and rat liver microsomal preparations. Species difference. Drug Metab Dispos, 1993; 21(5):874-82.

9. Madden S, Spaldin V, Park BK. Clinical pharmacokinetics of tacrine. Clin Pharmacokinet, 1995; 28(6):449-57.

10. Jann MW, Shirley KL, Small GW. Clinical pharmacokinetics and pharmacodynamics of 
cholinesterase inhibitors. Clin Pharmacokinet, 2002; 41(10):719-39.

11. Becquemont L, Ragueneau I, Le Bot MA, Riche C, Funck-Brentano $\mathrm{C}$, Jaillon $\mathrm{P}$. Influence of the CYP1A2 inhibitor fluvoxamine on tacrine pharmacokinetics in humans. Clin Pharmacol Ther, 1997; 61(6):619-27.

12. Sung JH, Yu KH, Park JS, Tsuruo T, Kim DD, Shim $\mathrm{CK}$, et al. Saturable distribution of tacrine into the striatal extracellular fluid of the rat: evidence of involvement of multiple organic cation transporters in the transport. Drug Metab Dispos, 2005; 33(3):440-8.

13. Koepsell H, Lips K, Volk C. Polyspecific organic cation transporters: structure, function, physiological roles, and biopharmaceutical implications. Pharm Res, 2007; 24(7):1227-51.

14. Zhang L, Zhang Y, Huang SM. Scientific and regulatory perspectives on metabolizing enzymetransporter interplay and its role in drug interactions: challenges in predicting drug interactions. Mol Pharm, 2009; 6(6):1766-74.

15. Swift B, Pfeifer ND, Brouwer KL. Sandwichcultured hepatocytes: an in vitro model to evaluate hepatobiliary transporter-based drug interactions and hepatotoxicity. Drug Metab Rev, 2010; 42(3):446-71.

16. Liu X, LeCluyse EL, Brouwer KR, Gan LS, Lemasters JJ, Stieger B, et al. Biliary excretion in primary rat hepatocytes cultured in a collagensandwich configuration. Am J Physiol, 1999; 277(1 Pt 1):G12-21.

17. Hoffmaster KA, Turncliff RZ, LeCluyse EL, Kim RB, Meier PJ, Brouwer KL. P-glycoprotein expression, localization, and function in sandwichcultured primary rat and human hepatocytes: relevance to the hepatobiliary disposition of a model opioid peptide. Pharm Res, 2004; 21(7):1294-302.

18. Turncliff RZ, Tian X, Brouwer KL. Effect of culture conditions on the expression and function of Bsep, Mrp2, and Mdr1a/b in sandwich-cultured rat hepatocytes. Biochem Pharmacol, 2006; 71(10):1520-9.

19. Abe K, Bridges AS, Yue W, Brouwer KL. In vitro biliary clearance of angiotensin II receptor blockers and 3-hydroxy-3-methylglutaryl-coenzyme A reductase inhibitors in sandwich-cultured rat hepatocytes: comparison with in vivo biliary clearance. J Pharmacol Exp Ther, 2008; 326(3):98390.

20. Liu X, Chism JP, LeCluyse EL, Brouwer KR, Brouwer KL. Correlation of biliary excretion in sandwich-cultured rat hepatocytes and in vivo in rats. Drug Metab Dispos, 1999; 27(6):637-44.

21. Fukuda H, Ohashi R, Tsuda-Tsukimoto M, Tamai I. Effect of plasma protein binding on in vitro-in vivo correlation of biliary excretion of drugs evaluated by sandwich-cultured rat hepatocytes. Drug Metab Dispos, 2008; 36(7):1275-82.
22. Ghibellini G, Vasist LS, Leslie EM, Heizer WD, Kowalsky RJ, Calvo BF, et al. In vitro-in vivo correlation of hepatobiliary drug clearance in humans. Clin Pharmacol Ther, 2007; 81(3):406-13.

23. Mohamed LA, Kaddoumi A. In vitro Investigation of Amyloid-beta Hepatobiliary Disposition in Sandwich Cultured Primary Rat Hepatocytes. Drug Metab Dispos, 2013.

24. Ekman L, Lindstrom B, Roxin P. Determination of tacrine and its 1-hydroxy metabolite in plasma using column liquid chromatography with ultraviolet detection. J Chromatogr, 1989; 494:397-402.

25. Seglen PO. Preparation of isolated rat liver cells. Methods Cell Biol, 1976; 13:29-83.

26. Lee JK, Marion TL, Abe K, Lim C, Pollock GM, Brouwer KL. Hepatobiliary disposition of troglitazone and metabolites in rat and human sandwich-cultured hepatocytes: use of Monte Carlo simulations to assess the impact of changes in biliary excretion on troglitazone sulfate accumulation. J Pharmacol Exp Ther, 2010; 332(1):26-34.

27. Yanni SB, Augustijns PF, Benjamin DK, Jr., Brouwer KL, Thakker DR, Annaert PP. In vitro investigation of the hepatobiliary disposition mechanisms of the antifungal agent micafungin in humans and rats. Drug Metab Dispos, 2010; 38(10):1848-56.

28. Prince RJ, Pennington RA, Sine SM. Mechanism of tacrine block at adult human muscle nicotinic acetylcholine receptors. J Gen Physiol, 2002; 120(3):369-93.

29. Petri N, Bergman E, Forsell P, Hedeland M, Bondesson U, Knutson L, et al. First-pass effects of verapamil on the intestinal absorption and liver disposition of fexofenadine in the porcine model. Drug Metab Dispos, 2006; 34(7):1182-9.

30. Giacomini KM, Huang SM, Tweedie DJ, Benet LZ, Brouwer KL, Chu X, et al. Membrane transporters in drug development. Nat Rev Drug Discov, 2010; 9(3):215-36.

31. Ohashi R, Tamai I, Yabuuchi H, Nezu JI, Oku A, Sai $\mathrm{Y}$, et al. $\mathrm{Na}(+)$-dependent carnitine transport by organic cation transporter (OCTN2): its pharmacological and toxicological relevance. $\mathrm{J}$ Pharmacol Exp Ther, 1999; 291(2):778-84.

32. Dresser MJ, Gray AT, Giacomini KM. Kinetic and selectivity differences between rodent, rabbit, and human organic cation transporters (OCT1). J Pharmacol Exp Ther, 2000; 292(3):1146-52.

33. Yabuuchi H, Tamai I, Nezu J, Sakamoto K, Oku A, Shimane $\mathrm{M}$, et al. Novel membrane transporter OCTN1 mediates multispecific, bidirectional, and pH-dependent transport of organic cations. J Pharmacol Exp Ther, 1999; 289(2):768-73.

34. Wu X, George RL, Huang W, Wang H, Conway SJ, Leibach FH, et al. Structural and functional characteristics and tissue distribution pattern of rat OCTN1, an organic cation transporter, cloned from 
placenta. Biochim Biophys Acta, 2000; 1466(12):315-27.

35. Dransfeld O, Gehrmann T, Kohrer K, Kircheis G, Holneicher C, Haussinger D, et al. Oligonucleotide microarray analysis of differential transporter regulation in the regenerating rat liver. Liver Int, 2005; 25(6):1243-58.

36. Duran JM, Peral MJ, Calonge ML, Ilundain AA. Functional characterization of intestinal L-carnitine transport. J Membr Biol, 2002; 185(1):65-74.

37. Kusuhara H, Suzuki H, Sugiyama Y. The role of Pglycoprotein and canalicular multispecific organic anion transporter in the hepatobiliary excretion of drugs. J Pharm Sci, 1998; 87(9):1025-40.
38. Mahar Doan KM, Humphreys JE, Webster LO, Wring SA, Shampine LJ, Serabjit-Singh CJ, et al. Passive permeability and P-glycoprotein-mediated efflux differentiate central nervous system (CNS) and non-CNS marketed drugs. J Pharmacol Exp Ther, 2002; 303(3):1029-37.

39. Loscher W, Potschka H. Blood-brain barrier active efflux transporters: ATP-binding cassette gene family. NeuroRx, 2005; 2(1):86-98. 